\title{
Primary Cerebral Lymphomatoid Granulomatosis Progressing to Methotrexate-associated Lymphoproliferative Disease Under Immunosuppressive Therapy
}

\author{
Hiroaki Tanaka ${ }^{1}$, Shogo Furukawa ${ }^{2}$, Yusuke Takeda ${ }^{3}$, Naomi Shimizu ${ }^{3}$, \\ Takeharu Kawaguchi ${ }^{1}$, Chika Kawajiri ${ }^{3}$, Shinichiro Hashimoto ${ }^{1}$, Toshiyuki Takagi ${ }^{1}$, \\ Shoichi Ito $^{2}$, Satoshi Ota ${ }^{4}$, Satoshi Kuwabara ${ }^{2}$ and Chiaki Nakaseko ${ }^{3}$
}

\begin{abstract}
Lymphomatoid granulomatosis (LYG) is an angiocentric and angiodestructive lymphoproliferative disease involving extranodal sites. Although LYG cerebral lesions are usually located adjacent to LYG pulmonary lesions, few reports have described the occurrence of primary cerebral LYG. We herein discuss a case of a 40year-old Japanese woman with primary cerebral LYG that caused various neurological symptoms for more than five years and progressed to methotrexate-associated lymphoproliferative disease under treatment with immunosuppressive therapy. This case suggests that primary cerebral LYG should be considered a lymphoid neoplasm manifesting as a primary brain tumor and a component of the differential diagnosis of chronic neuroinflammatory disorders.
\end{abstract}

Key words: primary cerebral lymphomatoid granulomatosis, methotrexate-associated lymphoproliferative disease, Epstein-Barr virus, methotrexate, rituximab

(Intern Med 54: 503-507, 2015)

(DOI: 10.2169/internalmedicine.54.2399)

\section{Introduction}

Primary cerebral lymphoid neoplasm is often difficult to diagnose because an invasive brain biopsy is required and because the quantity of biopsy specimen needed for the pathological analysis is limited. The most common primary cerebral lymphoid neoplasm is primary diffuse large B-cell lymphoma of the central nervous system (CNS), which is relatively easy to diagnose with limited biopsy specimens $(1,2)$. However, other primary cerebral lymphoid neoplasms are difficult to differentiate from neuroinflammatory disorders.

Lymphomatoid granulomatosis (LYG) is an angiocentric and angiodestructive lymphoproliferative disease that involves extranodal sites comprising Epstein-Barr virus (EBV)-positive B cells admixed with reactive T cells $(3,4)$.
The clinical manifestations of LYG are extremely variable, ranging from an indolent form to progressive disease similar to aggressive lymphoma (3-7). LYG is divided into three grades based on the proportion of large atypical EBVpositive B cells relative to reactive T-lymphocytes (4). EBVpositive atypical cells are infrequently detected in grade 1 lesions, although they are readily detected in grade 2 lesions (usually 5-20 per high-power field) on in situ hybridization (ISH). Grade 3 lesions comprise large atypical B cells, among which EBV-positive cells are numerous and easily identified. The presence of a uniform population of large atypical EBV-positive B-cells without a polymorphous background is beyond the spectrum of LYG and should be classified as diffuse large B-cell lymphoma (4). Although CNS lesions are found in $20-50 \%$ of LYG patients, usually proximal to sites of pulmonary LYG $(5,8)$, there are fewer reports of primary cerebral LYG versus primary pulmonary

${ }^{1}$ Department of Hematology, Oami Municipal Hospital, Japan, ${ }^{2}$ Department of Neurology, Chiba University Hospital, Japan, ${ }^{3}$ Department of Hematology, Chiba University Hospital, Japan and ${ }^{4}$ Department of Pathology, Chiba University Hospital, Japan

Received for publication December 27, 2013; Accepted for publication July 27, 2014

Correspondence to Dr. Hiroaki Tanaka, hiroakitanaka@oami-hp.jp 
LYG (9-13).

We herein describe the case of a patient with primary cerebral LYG, which caused various neurological symptoms for more than five years and progressed to methotrexateassociated lymphoproliferative disease (MTX-LPD) under treatment with immunosuppressive therapy.

\section{Case Report}

A 40-year-old Japanese woman with no relevant history developed metamorphopsia and right facial palsy in February 2007. Brain magnetic resonance imaging (MRI) revealed T2 high-intensity lesions in the bilateral occipital lobes. In August 2007, although a brain biopsy was performed due to suspicion of malignant lymphoma, the diagnosis was indefinite, and only inflammatory changes were observed. The patient received steroid pulse therapy, and her symptoms gradually improved. In December 2007, at which time the prednisolone (PSL) dose was tapered, she developed a new lesion in the left thalamus. In June 2011, she subsequently developed dizziness, hearing loss and a new pontine lesion. In April 2012, she exhibited paresthesia and weakness in the left upper and lower extremities, with progression of hearing loss and the onset of neurogenic diabetes insipidus. Steroid pulse therapy was administered and the dose of PSL was temporarily increased, followed by treatment with MTX (7.5 mg weekly) along with PSL in May 2012.

In December 2012, the patient developed diplopia, right ophthalmalgia and an ataxic gait and was immediately admitted. Upon admission, a physical examination revealed mild splenomegaly, although the superficial lymph nodes were not palpable. Her pupils were round and equal, with a weak light reflex in the right eye. In addition, the patient's capacity for abduction and adduction of the right eye was limited, and peripheral facial palsy with hearing loss in the left ear were observed. Finger-to-nose, knee-heel and hand pronation-supination tests revealed mild ataxia in the right upper and lower extremities. The laboratory findings were as follows: white blood cell count, $6.8 \times 10^{9} / \mathrm{L}$ (without abnormal cells); hemoglobin, $10.8 \mathrm{~g} / \mathrm{dL}$; platelet count, $344 \times 10^{9} /$ L; lactate dehydrogenase, $117 \mathrm{IU} / \mathrm{L}$; C-reactive protein, 0.2 $\mathrm{mg} / \mathrm{dL}$; and soluble interleukin-2 receptor (sIL-2R), 3,444 $\mathrm{IU} / \mathrm{mL}$. A serological test was negative for human immunodeficiency virus (HIV). The EBV titers were as follows: viral capsid antigen (VCA) immunoglobulin (Ig) $\mathrm{G}, \times 160$; VCA IgM, less than $\times 10$; early antigen $\operatorname{IgG}, \times 10$; and $\mathrm{EB}$ nuclear antigen, $\times 20$. Quantitative polymerase chain reaction for EBV DNA in the whole blood did not show a significant increase $\left(4 \times 10^{2}\right.$ copies $\left./ \mathrm{mL}\right)$. The cerebrospinal fluid cell count was $60 / \mu \mathrm{L}$; most cells were $\mathrm{CD}^{+} \mathrm{T}$-lymphocytes. The protein and glucose levels were $290 \mathrm{mg} / \mathrm{dL}$ and $43 \mathrm{mg} / \mathrm{dL}$, respectively. A bone marrow examination revealed no invasion of abnormal cells; however, brain contrast-enhanced MRI disclosed small enhanced T2 high-intensity lesions in the left parietal, left frontal and bilateral occipital lobes as well as the pons and bilateral cerebellar hemispheres
(Fig. 1). Thickening of the oculomotor nerve and loss of T1 high-intensity lesions in the posterior pituitary were also noted, although no lesions were detected in the right eye orbit. Meanwhile, whole-body computed tomography (CT) demonstrated multiple nodules in the bilateral lungs (Fig. 2a) and splenomegaly, and 2-deoxy-2-[ $\left.{ }^{[8} \mathrm{F}\right]$ fluorodeoxyglucose positron emission tomography (FDG-PET) revealed abnormal accumulation in the right axillary lymph node (Fig. 2b). A biopsy of the right axillary lymph node showed the dense proliferation of small atypical lymphocytes and sporadic large atypical lymphocytes (Fig. 3a) with large irregular atypical nuclei and nucleoli that were $\mathrm{CD} 20^{+}$ (Fig. 3b), $\mathrm{CD}^{5}$ and $\mathrm{CD} 10$. Many large lymphocytes were also positive for EBV-encoded small RNA (EBER), as determined on ISH (Fig. 3c). The Ki-67 index was more than $50 \%$ among large atypical lymphocytes (Fig. 3d). Based on these results, the patient was diagnosed with MTX-LPD. The biopsy specimen of the occipital lobe collected in August 2007 was retrospectively assessed, which displayed marked infiltration of inflammatory cells with few mediumsized CD20- and PAX-5-positive B-lymphocytes (Fig. 4a-c). A small number of EBER-positive medium-sized cells with furrowing were also found on ISH using EBER probes (Fig. 4d). The cerebral lesion was thus finally diagnosed as grade 1 LYG.

The weekly MTX $(7.5 \mathrm{mg})$ administration was terminated, and biweekly cycles of high-dose MTX $(3,500 \mathrm{mg} /$ $\left.\mathrm{m}^{2}\right)$ and rituximab $\left(375 \mathrm{mg} / \mathrm{m}^{2}\right)$ therapy were initiated. The patient's diplopia improved soon after the first cycle of treatment. Thereafter, her ataxic gait gradually improved and she was able to walk using crutches. We administered four courses of chemotherapy. The dose of PSL was reduced to 5 $\mathrm{mg}$ two weeks later, then to $2.5 \mathrm{mg}$ six weeks later. The course of treatment was then completed 10 weeks later. No neurological disorders were noted; however, the patient developed a persistent fever, general fatigue and anorexia. Brain contrast-enhanced MRI disclosed no new lesions. Although chest and abdominal CT showed the disappearance of multiple nodules in the bilateral lungs, no improvements in the splenomegaly were detected, and the sIL-2R level did not decrease from $>3,000 \mathrm{U} / \mathrm{mL}$. In June 2013, the patient ultimately died of aspiration pneumonia and septic shock.

\section{Discussion}

Diagnosing grade 1 LYG lesions using limited specimens, such as those obtained via needle biopsy, is difficult without applying EBER ISH technology because the lesions contain few EBV-positive large lymphoma cells compared with reactive T-lymphocytes. If large B-cell variants of high-grade lymphomas, such as primary diffuse large B-cell lymphoma of the CNS (CNS DLBCL) or intravascular large B-cell lymphoma (IVLBCL), are suspected based on the clinical and imaging findings, the lesions may be incorrectly diagnosed as inflammatory changes. Low-grade LYG is commonly treated with corticosteroids and/or other immunosup- 

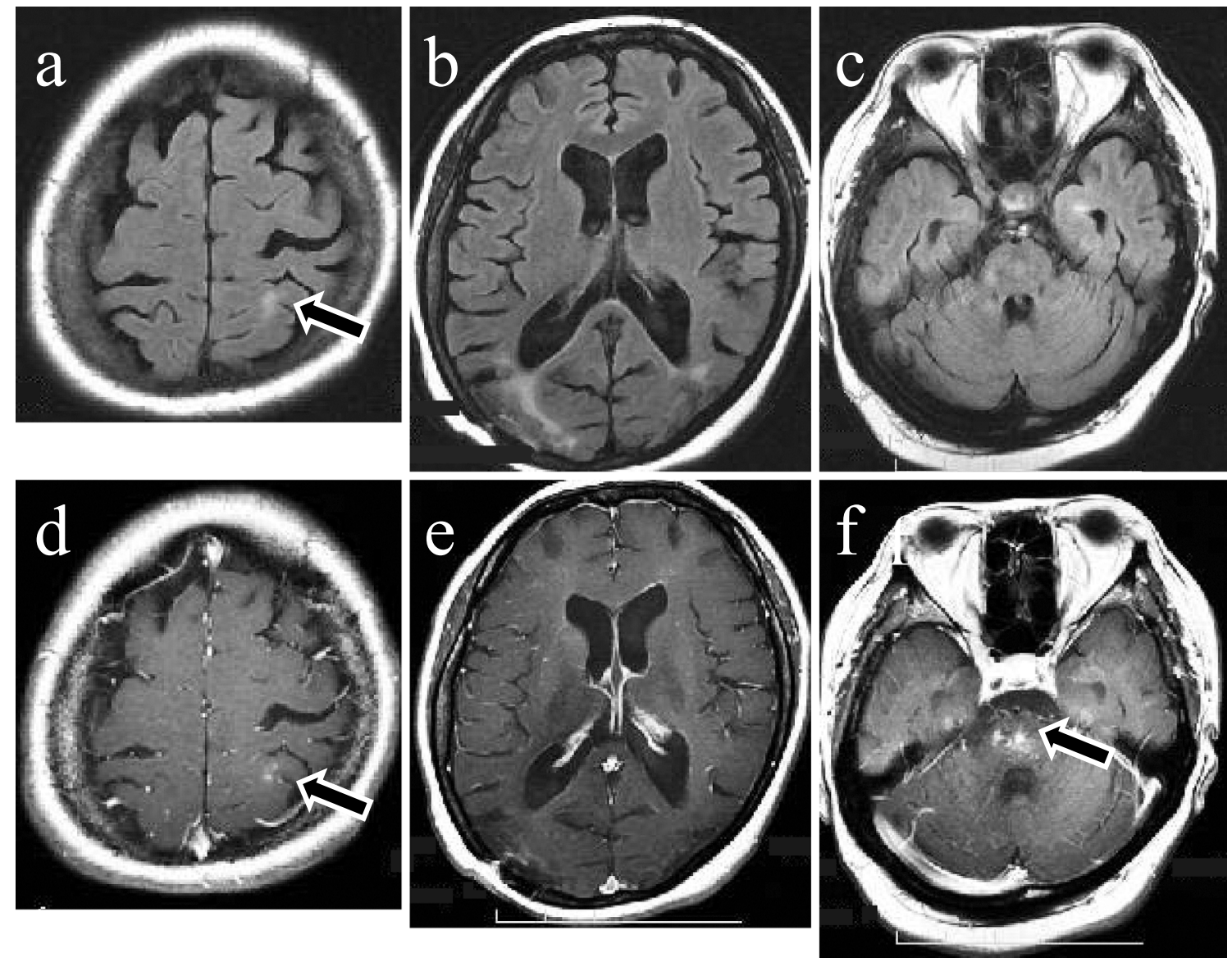

Figure 1. Contrast-enhanced brain magnetic resonance image obtained on hospital admission. Small enhanced T2 high-intensity lesions are observed in the left parietal lobe (a, d), left frontal lobe, bilateral occipital lobes (b, e), pons (c, f) and bilateral cerebellar hemispheres.
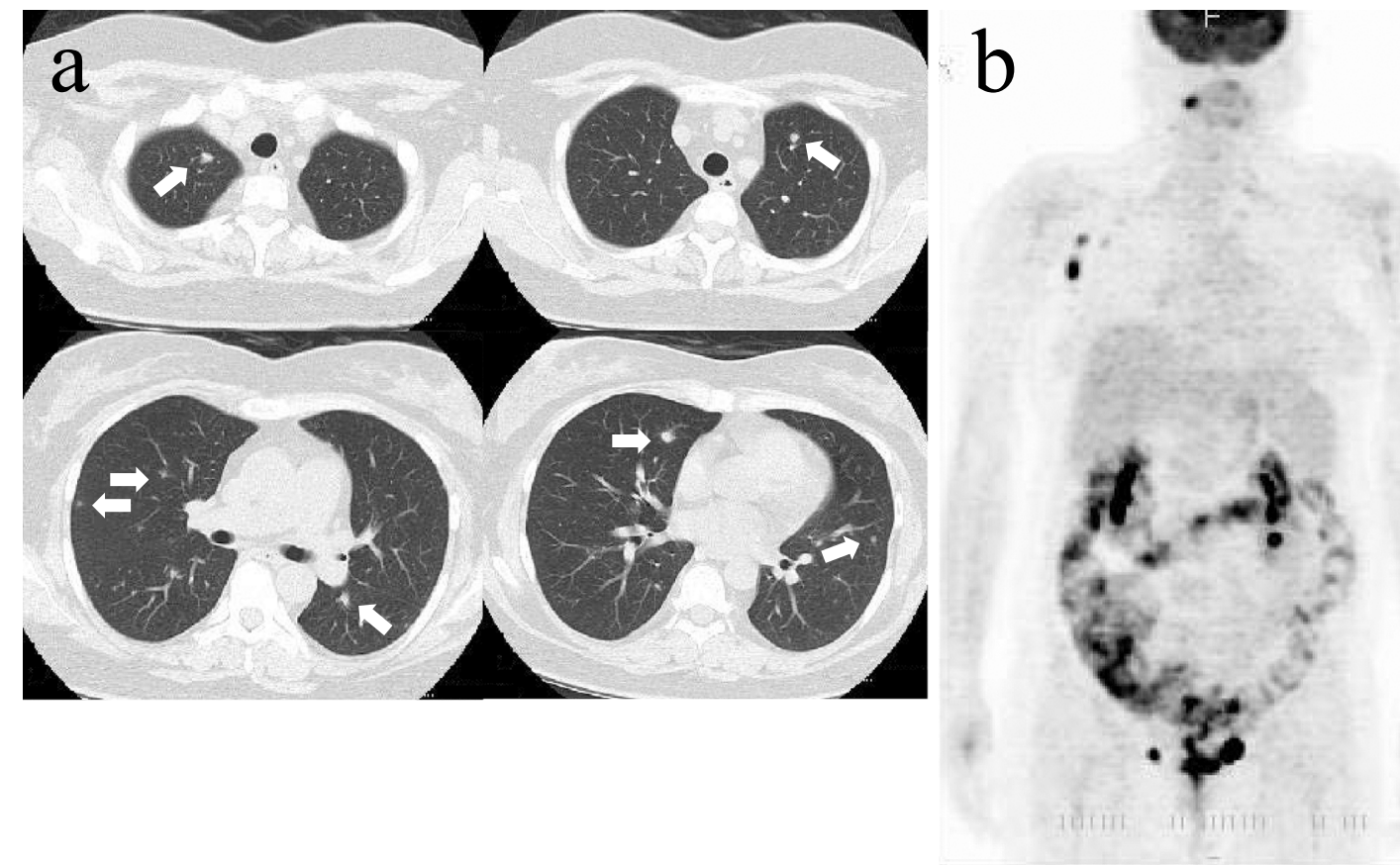

Figure 2. Whole-body computed tomography and 2-deoxy-2- $\left[{ }^{18} \mathrm{~F}\right]$-fluorodeoxyglucose positron emission tomography (FDG-PET) scans obtained on hospital admission. a: Multiple nodules were seen in the bilateral lungs. b: Lymphadenopathy is denoted by abnormal accumulation on FDG-PET. 

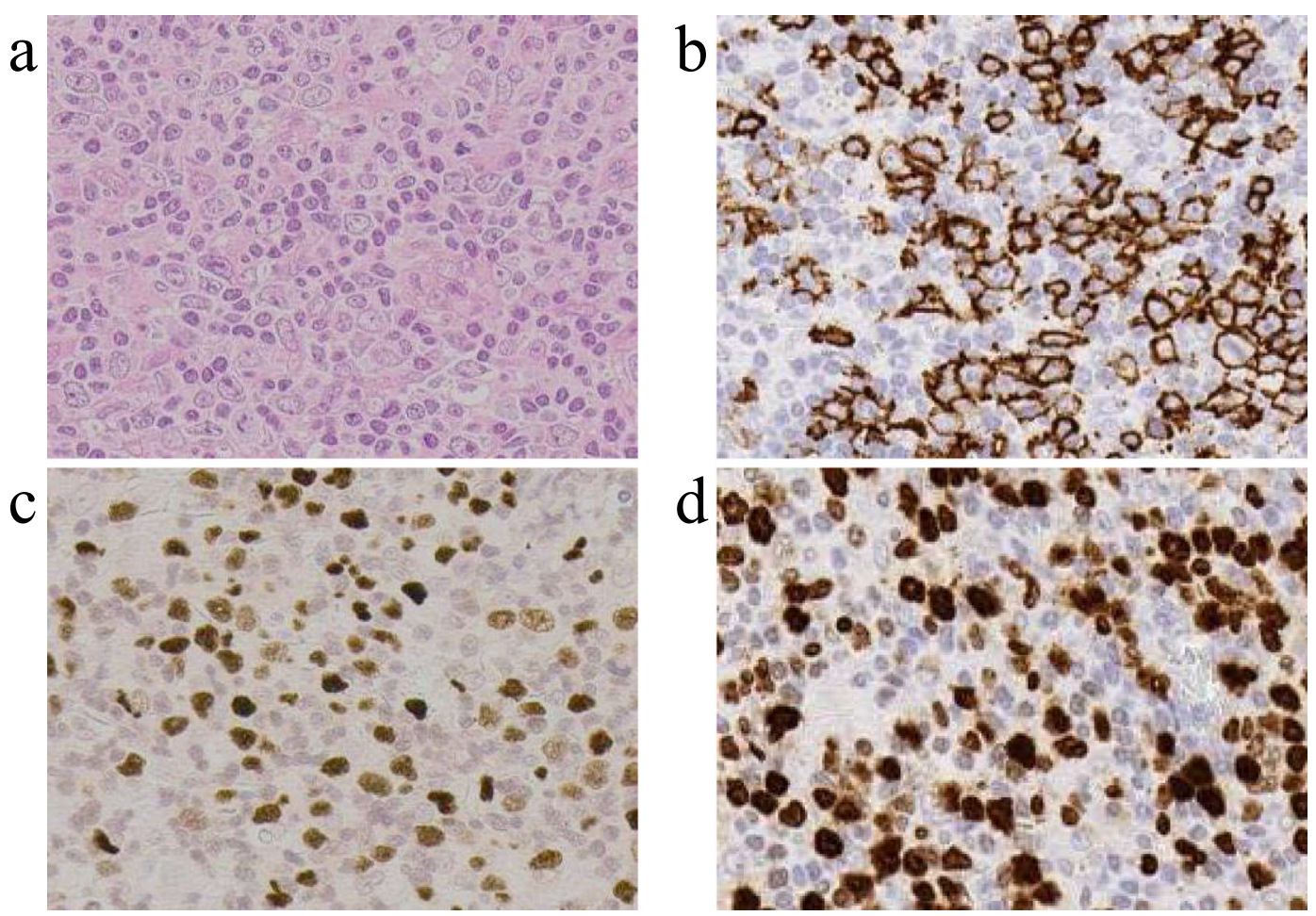

Figure 3. Pathological findings of the right axillary lymph node. a: Dense proliferation of small atypical lymphocytes and sporadic large atypical lymphocytes (Hematoxylin and Eosin staining: $\times 400)$. b: The large lymphocytes were $\mathrm{CD20}^{+}$, as determined on immunostaining $(\times 400)$. c: Many large lymphocytes were positive for Epstein-Barr-encoded small RNA, as detected according to in situ hybridization $(\times 400)$. d: Ki-67-positive cells accounted for more than $50 \%$ of the large atypical lymphocytes $(\times 400)$.
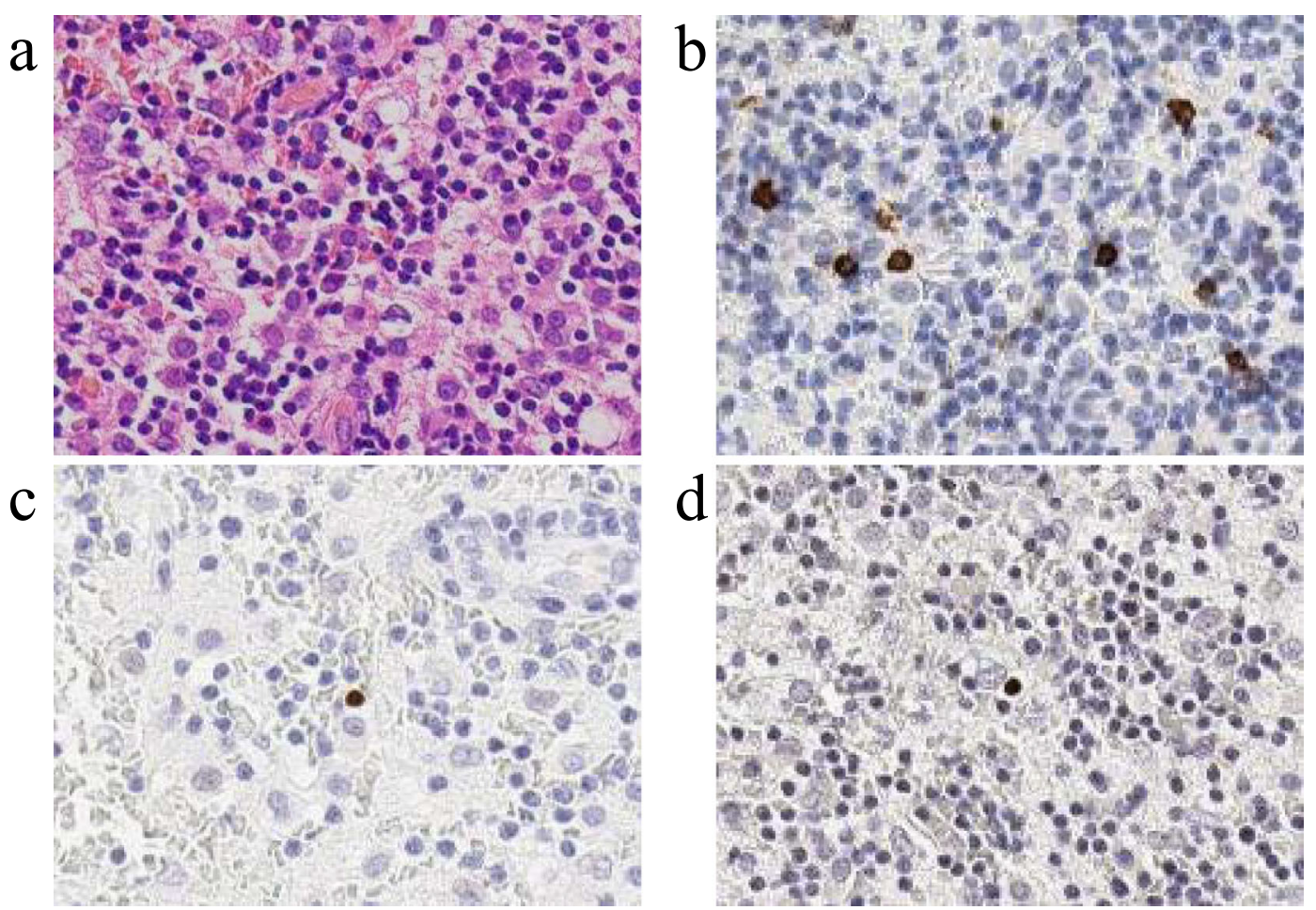

Figure 4. Pathological findings of the occipital lobe biopsy specimen. a: Marked inflammatory cell infiltration (Hematoxylin and Eosin staining: $\times 400$ ). b, c: Medium-sized CD20- (b) and PAX-5- (c) positive B-lymphocytes $(\times 400)$ were detected. d: Few Epstein-Barr-encoded small RNA-positive medium-sized cells with furrowing were noted $(\times 400)$. 
pressive drugs, which cause transient improvements in neurological and pulmonary symptoms. This transient improvement may also make it difficult to differentiate low-grade cerebral LYG from chronic neuroinflammatory disorders, and long-term disease control is rarely obtained in such cases (6).

Among the LYG patients undergoing MTX therapy, it is impossible to distinguish between MTX-LPD and LYG progression because both diseases show histologically similar features of polymorphic EBV-associated B-cell lymphoproliferation (14). In the present case, it was necessary to conduct a clonal analysis of the specimens in order to differentiate between these diseases. Nevertheless, performing an immunophenotypic comparison was difficult because the number of EBV-positive cells in the brain biopsy specimen was small. In addition, we were unable to analyze the Ig gene rearrangement because we did not store any brain specimens for later use.

After the disease progressed, rituximab and high-dose MTX therapy was temporarily effective in treating the cerebral and pulmonary lesions but ineffective in completely controlling all of the systemic lesions. In a large case series of LYG reported prior to the rituximab era, systemic LYG with CNS involvement was found to typically correlate with a poor prognosis, with a mortality rate of $86 \%$ at 14 months (compared with $66 \%$ among the patients without CNS involvement) (5). Rituximab was recently used to treat LYG patients, with a favorable toxicity profile (15-18), and has been reported to be effective against CNS lesions (18). In addition, a retrospective study of rituximab-containing chemotherapy for high-grade LYG documented a progressionfree survival of $40 \%$ at a median follow-up of 28 months (6). HIV-negative patients with primary cerebral LYG die approximately one year after receiving a diagnosis $(9,10)$, while patients with completely resectable tumoral cerebral lesions may survive for $>$ three years (11). Recently, various reports have described patients with EBVnegative primary cerebral LYG exhibiting a favorable prognosis with corticosteroid therapy alone (19-21). However, gene rearrangement studies have shown that many cases of the disorder are derived from T-cell monoclonal lymphoproliferative disease (21) and that EBV-negative primary cerebral LYG must be distinguished from $\operatorname{LYG}(4,7)$.

In conclusion, we herein described the successful diagnosis of primary cerebral LYG that progressed to MTX-LPD under immunosuppressive therapy. The present case suggests that this disease should be considered a lymphoid neoplasm manifesting as a primary brain tumor (e.g., CNS DLBCL or IVLBCL) and a component of the differential diagnosis of chronic neuroinflammatory disorders.

The authors state that they have no Conflict of Interest (COI).

\section{References}

1. Jellinger KA, Paulus W. Primary central nervous system lymphomas--new pathological developments. J Neurooncol 24: 3336, 1995.

2. Kluin PM, Deckert M, Ferry JA. Primary diffuse large B-cell lymphoma of the CNS. In: WHO classification of tumors of haematopoietic and lymphoid tissues. 4th ed. Swerdlow SH, Campo E, Harris NL, et al, Eds. IARC, Lyon, 2008: 240-241.

3. Liebow AA, Carrington CR, Friedman PJ. Lymphomatoid granulomatosis. Hum Pathol 3: 457-558, 1972.

4. Pittaluga S, Wilson WH, Jaffe E. Lymphomatoid granulomatosis. In: WHO classification of tumors of haematopoietic and lymphoid tissues. 4th ed. Swerdlow SH, Campo E, Harris NL, et al, Eds. IARC, Lyon, 2008: 247-249.

5. Katzenstein AL, Carrington CB, Liebow AA. Lymphomatoid granulomatosis: a clinicopathologic study of 152 cases. Cancer $\mathbf{4 3}$ : 360-373, 1979.

6. Roschewski M, Wilson WH. Lymphomatoid granulomatosis. Cancer J 18: 469-474, 2012.

7. Colby TV. Current histological diagnosis of lymphomatoid granulomatosis. Mod Pathol 25: S39-S42, 2012.

8. Patsalides AD, Atac G, Hedge U, et al. Lymphomatoid granulomatosis: abnormalities of the brain at MR imaging. Radiology 237: 265-273, 2005.

9. Takeishi G, Moroki K, Kawasoe T, et al. Spontaneous regression and regrowth of central nervous system lymphomatoid granulomatosis: case report. Neurol Med Chir (Tokyo) 51: 801-804, 2011.

10. Kagawa K, Ishida T, Okada H. Primary central nervous system lymphomatoid granulomatosis: a case report. No Shinkei Geka (Neurological Surgery) 39: 883-889, 2011 (in Japanese, Abstract in English).

11. Gonzalez-Darder JM, Vera-Román JM, Pesudo-Martínez JV, Cerda-Nicolas M, Ochoa E. Tumoral presentation of primary central nervous system lymphomatoid granulomatosis. Acta Neurochir (Wien) 153: 1963-1970, 2011.

12. Wyen C, Stenzel W, Hoffmann C, Lehmann C, Deckert M, Fatkenheuer G. Fatal cerebral lymphomatoid granulomatosis in an HIV-1-infected patient. J Infect 54: e175-e178, 2007.

13. Kiryu $S$, Okubo $T$, Takeuchi $K$, et al. Magnetic resonance imaging and diffusion tensor analysis of lymphomatoid granulomatosis of the brain. Acta Radiol 47: 509-513, 2006.

14. Gaulard P, Swerdlow SH, Harris NL, Jaffe ES, Sundtrom C. Other iatrogenic immunodeficiency-associated lymphoproliferative disorders. In: WHO classification of tumors of haematopoietic and lymphoid tissues. 4th ed. Swerdlow SH, Campo E, Harris NL, et al, Eds. IARC, Lyon, 2008: 350-351.

15. Castrale C, El Haggan W, Chapon F, et al. Lymphomatoid granulomatosis treated successfully with rituximab in a renal transplant patient. J Transplant 2011: 865957, 2011.

16. Jung KH, Sung HJ, Lee JH, et al. A case of pulmonary lymphomatoid granulomatosis successfully treated by combination chemotherapy with rituximab. Chemotherapy 55: 386-390, 2009.

17. Ishiura H, Morikawa M, Hamada M, et al. Lymphomatoid granulomatosis involving central nervous system successfully treated with rituximab alone. Arch Neurol 65: 662-665, 2008.

18. Lucantoni C, De Bonis P, Doglietto F, et al. Primary cerebral lymphomatoid granulomatosis: report of four cases and literature review. J Neurooncol 94: 235-242, 2009.

19. Nishihara $H$, Nakasato $M$, Sawa $H$, et al. A case of central nervous system lymphomatoid granulomatosis; characteristics of PET imaging and pathological findings. J Neurooncol 93: 275-278, 2009.

20. Shimada S, Ueno H, Yamasaki F, et al. A case of central nervous system lymphomatoid granulomatosis successfully treated with corticosteroids. Brain Nerve 64: 85-87, 2012.

21. Nishihara H, Tateishi U, Itoh $T$, Nagashima K, Tanaka S. Immunohistochemical and gene rearrangement studies of central nervous system lymphomatoid granulomatosis. Neuropathology 27: 413-418, 2007.

(C) 2015 The Japanese Society of Internal Medicine http://www.naika.or.jp/imonline/index.html 